\title{
Implementation of Intelligent Controlling Mechanism to Improve Conversion Efficiency of Solar PV Module
}

Kakarla Deepti

Department of Electronics and Communication Engineering, Vasavi College of Engineering, Hyderabad

To Cite this Article

Kakarla Deepti, "Implementation of Intelligent Controlling Mechanism to Improve Conversion Efficiency of Solar PV Module", International Journal for Modern Trends in Science and Technology, Vol. 06, Issue 05, May 2020, pp.: 168-172; https://doi.org/10.46501/IJMTST060526

Article Info

Received on 24-April-2020, Revised on 15-May-2020, Accepted on 20-May-2020, Published on 24-May-2020.

\section{ABSTRACT}

The research article aims at an intelligent control method to improve conversion efficiency of solar photovoltaic module by tracking maximum operating point irrespective of variations in temperature and irradiance. A novel hybrid maximum power point based on learning automata is proposed. The algorithm works in two stages, first the learning automata detects the temperature and irradiation of light incidenting on PV module, second it identifies the zone of operation and adjusts the duty cycle of DC-DC converter. This implementation is done by designing the learning automata using artificial neural network and the adjustment of duty cycle is implemented with fuzzy logic controller. The design is verified using matlab/simulink environment.

KEYWORDS: Artificial neural network,Fuzzy logic controller, DC-DC converter, Photo voltaic module.

Copyright (C) 2014-2020 International Journal for Modern Trends in Science and Technology

DOI: https://doi.org/10.46501/IJMTST060526

\section{INTRODUCTION}

According to 2014 international energy agency data, it indicates that the consumption of fossil fuels makes around $80 \%$ of total energy consumption. Percentage of nuclear energy usage is $9.9 \%$, renewable and other energy sources are used by about $7 \%$ of whole energy production sources. As per international energy agency federation, the demand on energy is increasing by $2 \%$ yearly worldwide[1]. To overcome the problem caused by non clean energy consumption, the raise in demand of energy has to be met by renewable sources. Solar energy is the utmost conveniently used sustainable energy source[2]. The PV module has inherent drawbacks of low conversion efficiency and high initial establishment cost. The low conversion efficiency is due to the dependency variation in ambient temperature and irradiance. To overcome this many Maximum power point tracking (MPPT) algorithms have been developed[3]. The researchers are now adopting intelligent methods in tracking the maximum power point of PV cell[4]. These techniques have the advantages of being robust, simple in design and minimal requirement for accurate mathematical modeling. The robustness of fuzzy methods depends on effectiveness of selection of parameters, definition of membership functions and fuzzy rules[5]. In the proposed system initially the photovoltaic panel has been replicated with the help of mathematical equations in simulink. Then a photovoltaic subsystem with Cuk converter has 
been designed. After that the simulink model with MPPT controller working on the principle of Incremental conductance algorithm has been modeled and the efficiency of this model with the fuzzy model was compared by considering various conditions of temperature and irradiance. A hybrid method involving Artificial Neural Network (ANN) based Fuzzy Logic Control (FLC) for standalone PV system to extract potential maximum power from PV system under changing temperature and irradiance. The objective of controller is to increase tracking efficiency and to overcome the inherent drawbacks in conventional maximum power point tracking algorithms.

\section{MODELLING OF PV MODULE IN SIMULINK}

The replica of the PV module is implemented in simulink by using suitable mathematical equations that justify the single cell circuit model of PV cell. The simulink model is shown in Fig.1.The supporting mathematical equations are not presented here as the objective of article is towards modeling of ANN.

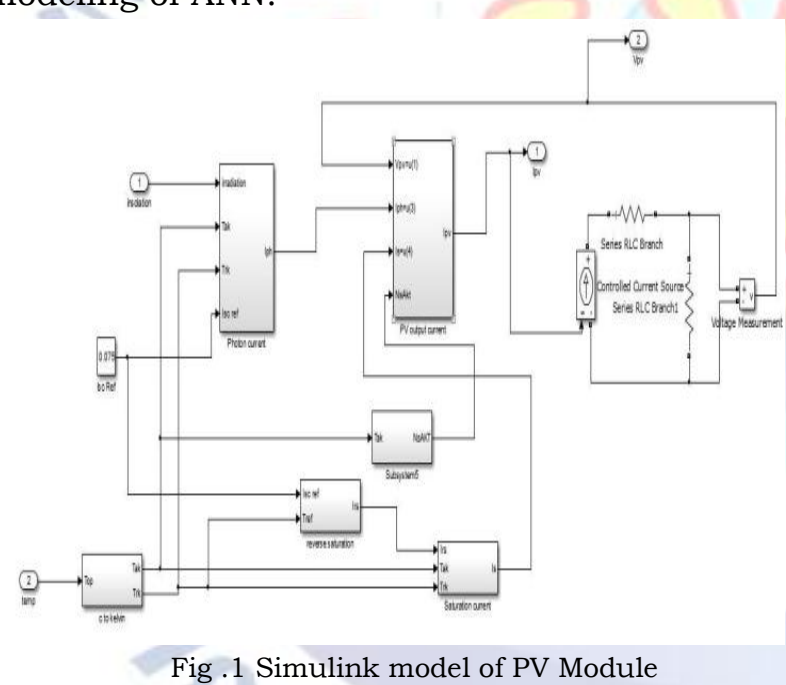

The characteristics of modeled PV module at $25^{\circ} \mathrm{C}$ and varying irradiance are shown in Fig.2.In Table .1 the summary of Values obtained from the waveform is listed. The column of values at $25^{\circ} \mathrm{C}$ and $1000 \mathrm{w} / \mathrm{m}^{2}$ indicate the PV module characteristics at Standard test conditions. The simulink model includes the blocks of Photon current ,Reverse saturation current, PV output current and signal conditioning circuit to convert the physical input to compatible simulink input.

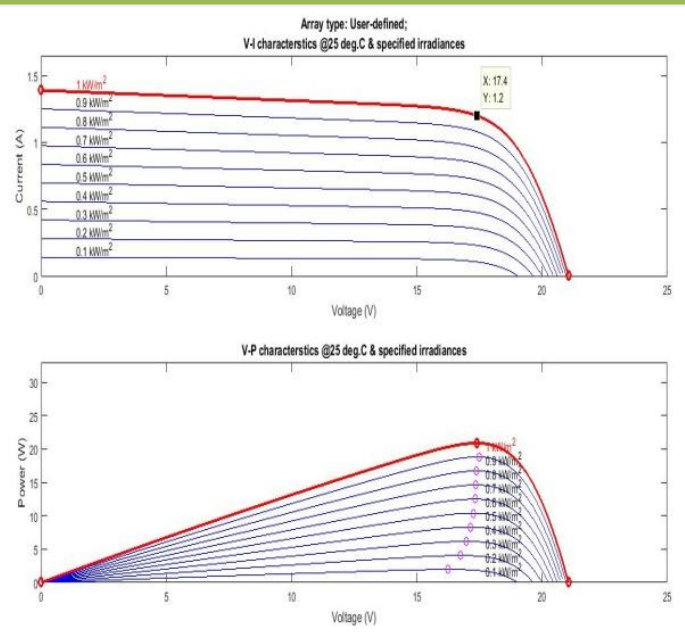

Fig .2 Characteristics of PV Module at constant temperature and varying irradiance

Table 1: Summary of values in Fig. 1

\begin{tabular}{|l|l|l|l|l|}
\hline Irradiance & $\begin{array}{l}1000 \\
\mathrm{w} / \mathrm{m}^{2}\end{array}$ & $\begin{array}{l}800 \\
\mathrm{w} / \mathrm{m}^{2}\end{array}$ & $\begin{array}{l}600 \\
\mathrm{w} / \mathrm{m}^{2}\end{array}$ & $\begin{array}{l}400 \\
\mathrm{w} / \mathrm{m}^{2}\end{array}$ \\
\hline Isc(A) & 1.39 & 1.35 & 1.32 & 1.26 \\
\hline Voc(V) & 21.06 & 20.88 & 20.71 & 20.05 \\
\hline Vmpp(V) & 17.40 & 17.38 & 17.32 & 17.14 \\
\hline Impp(A) & 1.20 & 0.96 & 0.72 & 0.48 \\
\hline $\mathrm{P}(\mathrm{w})$ & 20.88 & 16.72 & 12.51 & 8.28 \\
\hline
\end{tabular}

III. MODELING OF ANN IN SIMULINK

An artificial neural network is a network that attempts to imitate brain functions. For the human brain to perform a task, millions of neurons are ought to work in a perfect harmony. Similar to the function of neurons in ANN, a task can be completed by loading a huge data set at the learning process. To attain data set, the system behavior under all possible conditions should be known, through experimentation. ANN's are designed to do a specific task through a learning process. It is an indirect soft computing method of making the system/machine to learn the behavior with provision of inputs and the desired output data.

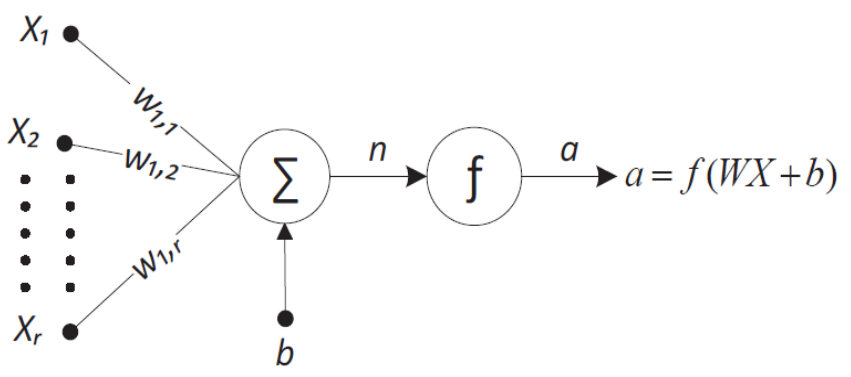

Fig .3. General structure of ANN

The input vector $\mathrm{x}$ is multiplied by weight vector $\mathrm{W}$. This product of $\mathrm{W}^{*} \mathrm{x}$, is added to a bias $\mathrm{b}$ to form $\mathrm{a}$ net input $n$. The net input ' $n$ ' is then the input to a neuron activation function to produce an output ' $a$ ' 
as shown in Fig. 3. The ANNs are one of the best suited soft computing techniques in analyzing the behavior of non linear response of the system. The maximal operating point of a PV module continuously changes with variation in temperature and irradiance effects. These non linear characteristics of PV module are given as input to ANN and the output voltage and current for those suitable inputs are recorded and are given as inputs to FLC.

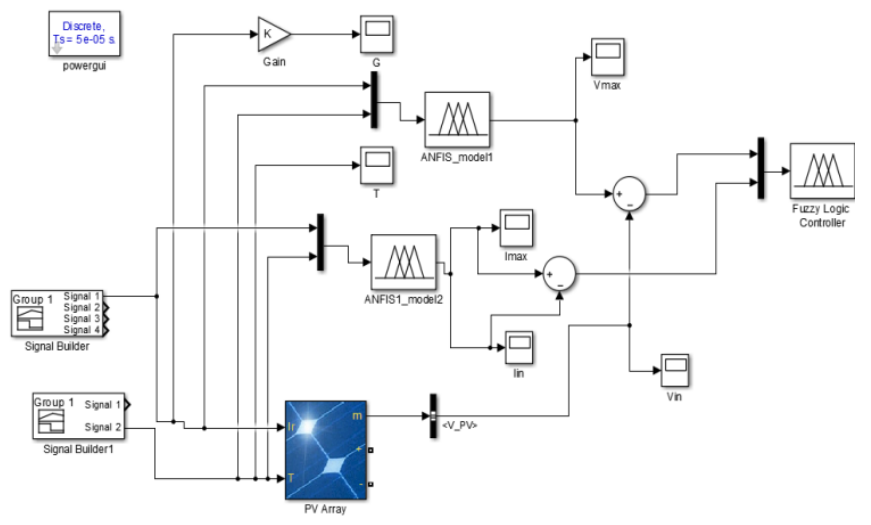

Fig .4. Modeling of ANN in simulink

The Simulink model of ANN is represented in Fig.4.The PV module is designed with the specified parameters as given in Table 1 . and is represented in Fig.5. The PV module is selected with user defined and the electrical parameters are assigned in the respective blocks. The inputs at signal builder blocks are given for possible variations in irradiation and temperature and are represented in Fig. 6 and 7. The gain block $\mathrm{K}$ before the irradiance is taken as multiplication factor of 1000.The ANFIS_model1 generates the output voltage from the configured PV module and ANFIS1_model2 generates the output current of PV module. These two outputs are applied as inputs to the FLC. The signal builder blocks and training data set loaded are common for both inference systems.

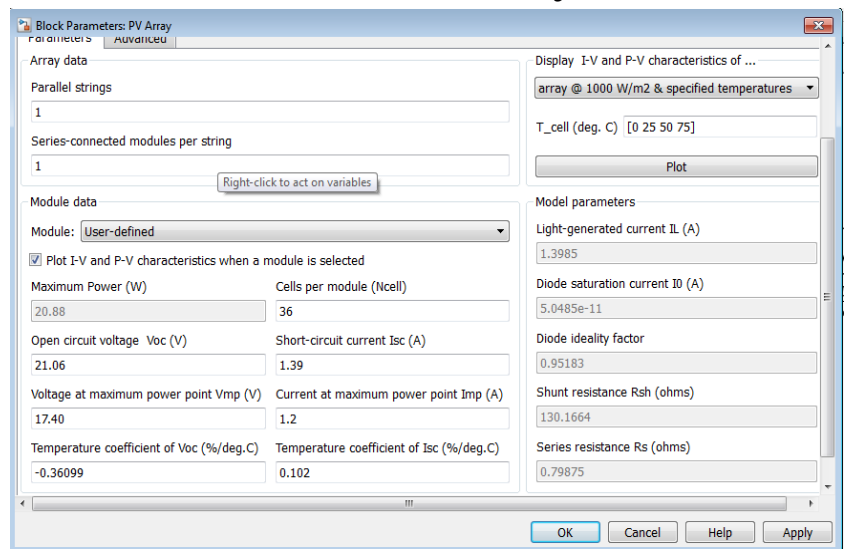

Fig .5. Assignment of Bock parameters of PV module

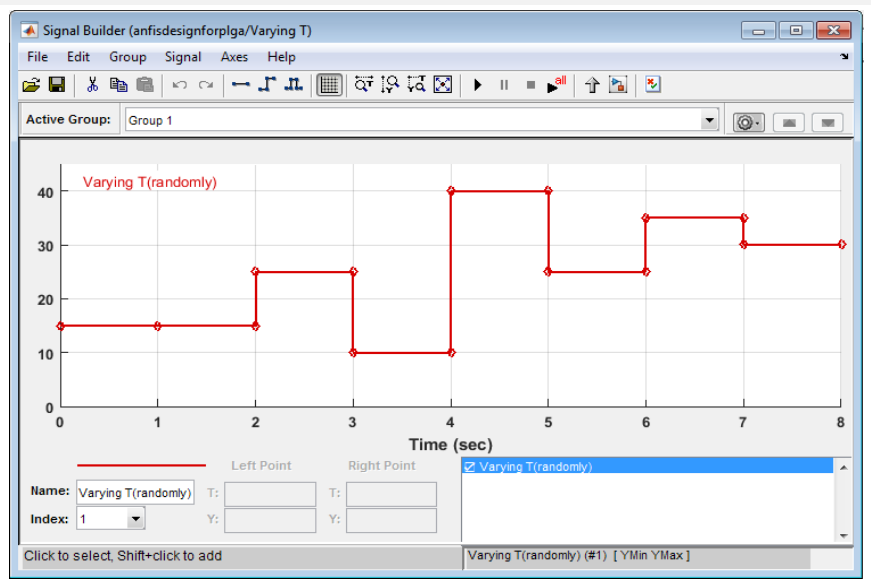

Fig .6.signal builder block for variation in temperature

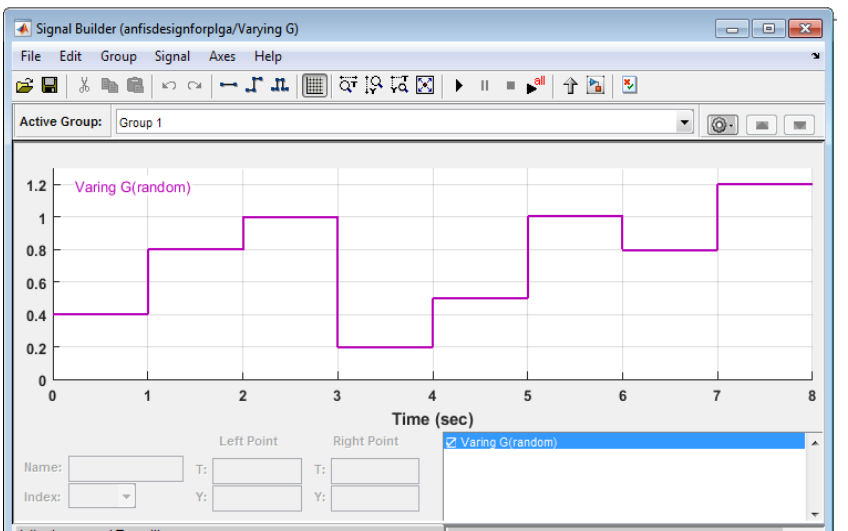

Fig .7.signal builder block for variation in irradiance

The training to the neural network is done by loading the data set. The data set is obtained based on hardware calibrations done using PV module. Experimentation is done to load the dataset that relates the behavior of the PV module for various possible irradiances and temperature. Ambient temperature is measured by interfacing DHT11 sensor and irradiance through lux meter. While measuring irradiance, lux meter has to be placed at the four corners and centre of the PV module, and the average of these five values is considered as irradiance. The experimentation is done in dark room environment and the irradiance effect is generated by connecting bulbs. A huge data set of samples has been considered to load as training data.

The ANN system has two inputs: Temperature and Irradiance for both systems and output of one is voltage and the other is current. The inference system for ANFIS to extract current is shown in Fig. 8 For Neural Networks, the most preferred inference system is the "Takagi-Sugeno" model as it is computationally capable and works well with adaptation and optimization techniques with high accuracy.Fig. 9 shows the membership function for input variable temperature. Similarly the 
membership functions for input and output variables are generated in simulink.

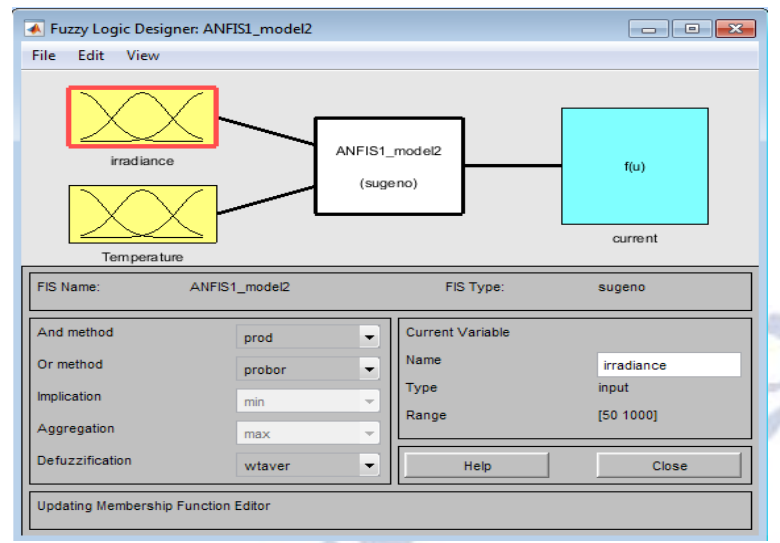

Fig.8. FIS Editor for output current in Simulink

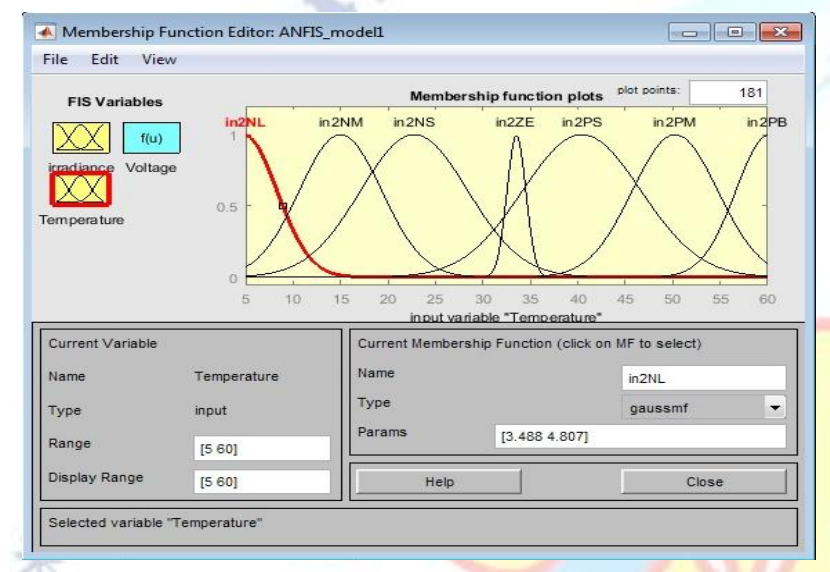

Fig.9. Membership function for Temperature input

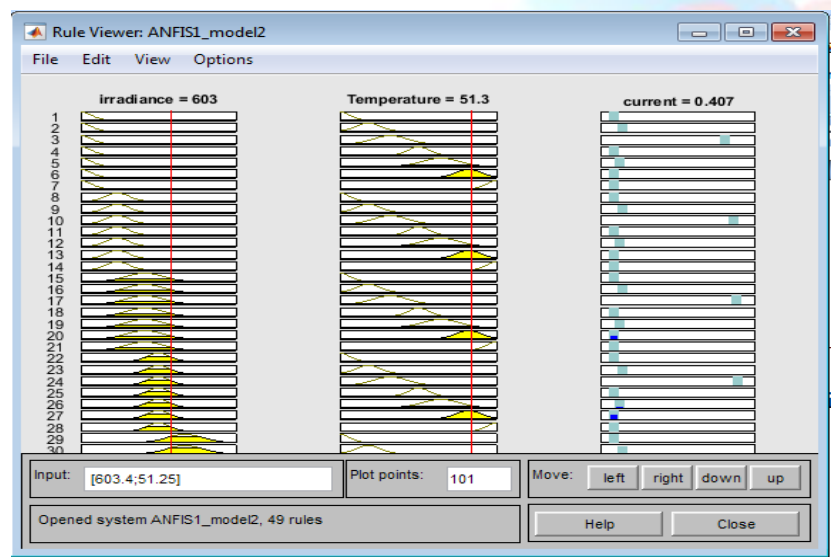

Fig.10.ANFIS Rule viewer

The Rule Viewer displays a roadmap of the whole artificial neural fuzzy inference process. It contains the input and output windows and each window has a vertical slider. By dragging this slider, the outputs for the corresponding current input values are visible on the top of the windows. In the text field at lower left, user can enter specific input values. The fuzzy rule viewer indicates the status of error, change in error along with the cursor and the corresponding rule viewer for ANFIS structure to attain output current is shown in Fig. 10.
The number of times the algorithm goes through the entire data set is called an epoch. An epoch is completed each time the algorithm has seen all samples in the dataset. Thus, more the number of the epochs, the better would be the learning process by the model. In the present work, the total number of epochs was set to 3,000. In neural network terminology, Error tolerance refers to the ability of an algorithm to learn when the examples received have been corrupted in some way. Noise can interfere with the learning process at different levels. The desired margin of error must be kept as low as possible without hindering the performance of the model. If the dataset is huge, extremely low values of errors can be achieved. The error tolerance in the present work was set to $0 \%$. Although after training, it reached only to a value of $9.4 \%$ due to a relatively small dataset. The result is shown in Fig. 11.

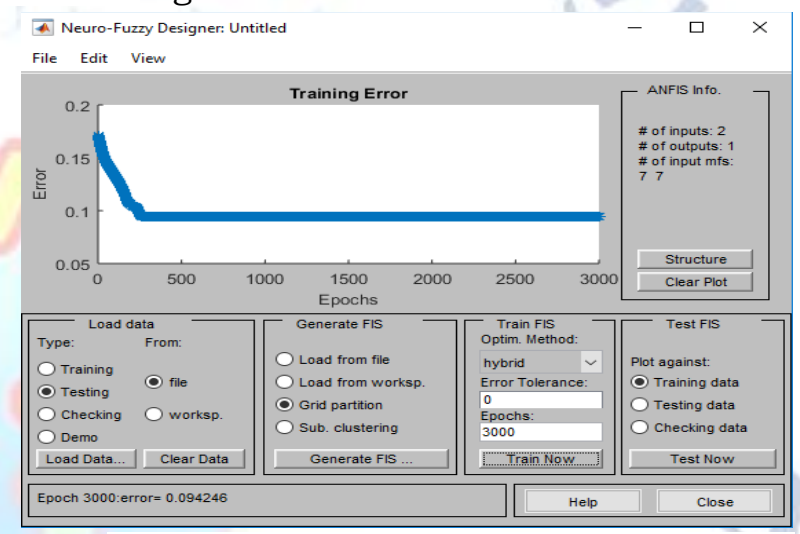

Fig. 11. Error Tolerance obtained after training the Neural Network for 3000 epochs

\section{RESULTS}

The performance is verified with a random variation in both temperature and irradiance. Temperature variation is over a range of $5^{\circ} \mathrm{c}$ to $60^{\circ} \mathrm{C}$ and irradiance variation is over a range of 100 $\mathrm{w} / \mathrm{m}^{2}$ to $1000 \mathrm{w} / \mathrm{m}^{2}$. The outputs obtained for current and voltage after implementation of ANN are shown in Fig. 12 and Fig.13. From the training data set, when the temperature is 35 and irradiance is $1000 \mathrm{w} / \mathrm{m}^{2}$ between $6 \mathrm{~s}$ to $7 \mathrm{~s}$, the voltage is $12.4 \mathrm{~V}$ and current is $0.36 \mathrm{~A}$. From the simulation the approximate value of temperature is 35.2 and irradiance is $1000 \mathrm{w} / \mathrm{m} 2^{\text {the voltage and }}$ current obtained are $12.5 \mathrm{~V}$ and $0.34 \mathrm{~A}$. These values are optimal as they are within the range of error tolerance 


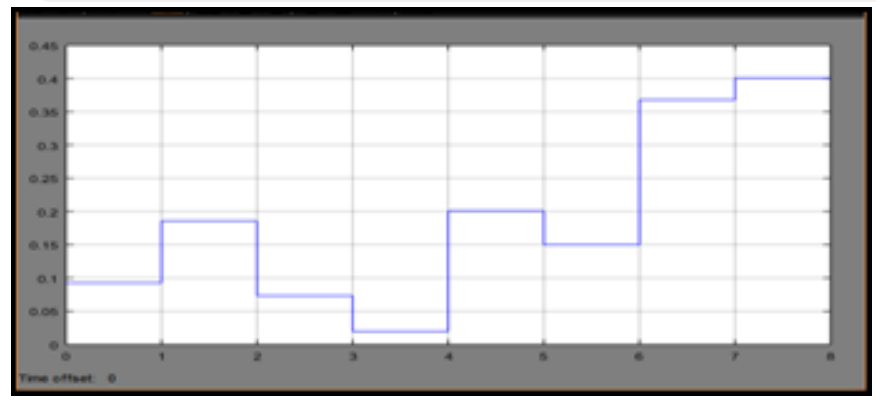

Fig. 12.Output current of ANN system

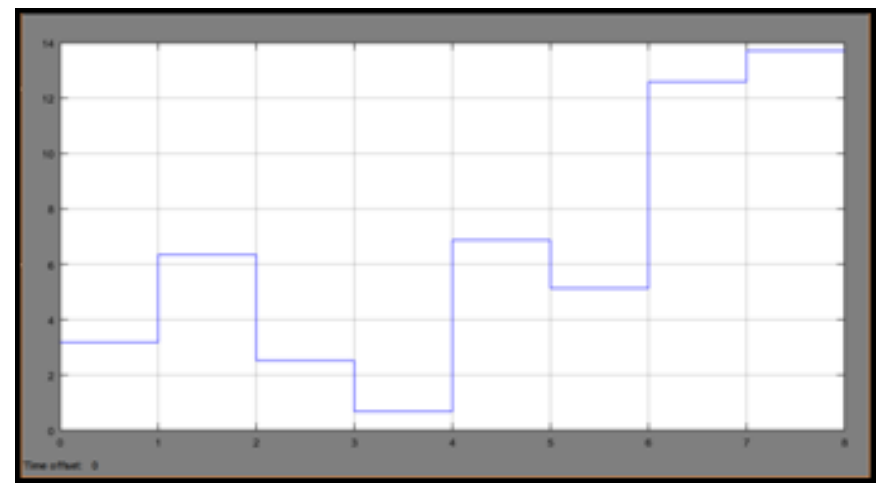

Fig.13.Output voltage of ANN system

\section{Conclusion}

It can be concluded that the implemented Network extracts the values of voltage and current of the PV module with maximum correlation. In implementing any intelligent hybrid controller design the outputs of ANN that replicates the behavior of the module are given as inputs.

\section{REFERENCES}

[1] VladimirV.R.Scarpa,SimoneBuso,Giorgio,Spiazzi, "Low Complexity MPPT technique Exploiting the PV module MPP locus characterization",IEEE Transactions on Industrial Electronics,vol.56,Issue 5,pp1531-1538,May 2009.

[2] P. Suskis and I. Galkin, "Enhanced PV Panel Model for MATLAB-Simulink Enviornment Considering Solar Cell Junction Capacitiance," in Industrial Electronics Society, IECON 2013 - 39 th Annual Conference of the IEEE, pp. 1613-1618.

[3] R.Kempener, P.Komor , A.Hoke, "Smart Grid and Renewables: A Guide for Efefctive Deployment.," International Renewable Energy Agency: IRENA, Masdar, 2013

[4] K.S.Tam, P.Kumar, M.Foreman, "Enahncing the Utilization of Photovoltic Power Generation by Superconductive 172 xtremum Energy Storage.," IEEE Transactions on Energy Conversion, vol. 4, no. 3, pp. 314-321, 2002.

[5] J. H. R. Enslin, D. B. Snyman, Simplified feed-forward control of the maximum power point tracker for PV applications, Proc. Int. Conf. IEEE Power Electron. Motion Control, 1992, vol. 1, pp. 548-553. 